\title{
REVIEW ARTICLE \\ GPR3, GPR6, and GPR12 as novel molecular targets: their biological functions and interaction with cannabidiol
}

\author{
Alyssa S. Laun ${ }^{1}$, Sarah H. Shrader ${ }^{1}$, Kevin J. Brown ${ }^{1}$ and Zhao-Hui Song ${ }^{1}$
}

The G protein-coupled receptors 3, 6, and 12 (GPR3, GPR6, and GPR12) comprise a family of closely related orphan receptors with no confirmed endogenous ligands. These receptors are constitutively active and capable of signaling through $\mathrm{G}$ protein-mediated and non-G protein-mediated mechanisms. These orphan receptors have previously been reported to play important roles in many normal physiological functions and to be involved in a variety of pathological conditions. Although they are orphans, GPR3, GPR6, and GPR12 are phylogenetically most closely related to the cannabinoid receptors. Using $\beta$-arrestin2 recruitment and cAMP accumulation assays, we recently found that the nonpsychoactive phytocannabinoid cannabidiol (CBD) is an inverse agonist for GPR3, GPR6, and GPR12. This discovery highlights these orphan receptors as potential new molecular targets for CBD, provides novel mechanisms of action, and suggests new therapeutic uses of CBD for illnesses such as Alzheimer's disease, Parkinson's disease, cancer, and infertility. Furthermore, identification of CBD as a new inverse agonist for GPR3, GPR6, and GPR12 provides the initial chemical scaffolds upon which potent and efficacious agents acting on these receptors can be developed, with the goal of developing chemical tools for studying these orphan receptors and ultimately new therapeutic agents.

Keywords: orphan receptors; GPR3; GPR6; GPR12; cannabidiol; inverse agonist; eurite outgrowth; Alzheimer's disease; neuropathic pain; obesity; infertility.

Acta Pharmacologica Sinica (2019) 40:300-308; https://doi.org/10.1038/s41401-018-0031-9

\section{INTRODUCTION}

The G protein-coupled receptors 3, 6, and 12 (GPR3, GPR6, and GPR12) comprise a family of closely related receptors. These three receptors share approximately $60 \%$ amino acid identity [1]. They are also phylogenetically related to the spingosine-1-phosphate (S1P) receptor, lysophosphatidic acid receptor, melanocortin receptor, and cannabinoid receptors $[2,3]$. Despite being related, the similarity of GPR3, GPR6, and GPR12 to other receptor groups is not sufficient to suggest a common ligand. Since GPR3, GPR6, and GPR12 have no confirmed endogenous ligands, they are still classified as orphan receptors [4].

Recently, we have identified orphan receptors GPR3, GPR6, and GPR12 as novel targets for the phytocannabinoid cannabidiol (CBD) [5-7]. In this review, we will first survey the current literature detailing the molecular and functional aspects of GPR3, GPR6, and GPR12; this will be followed by a description of our recent discoveries involving $C B D$ as a novel inverse agonist for these three orphan receptors. We will conclude by providing implications of our findings with regard to the mechanism of actions of $\mathrm{CBD}$ and the development of more potent, CBD template-based ligands for GPR3, GPR6, and GPR12.

\section{CLONING/CHROMOSOMAL LOCALIZATION/DISTRIBUTION}

$\mathrm{G}$ protein-coupled receptor 3

GPR3 was first cloned from a mouse cDNA library in 1993 [8]

before being cloned from human genomic libraries by several independent groups [1,9-11]. Recently, it was also cloned from a porcine cDNA library [12]. Marchese et al. [9] mapped GPR3 to chromosome 1p35-1p36.1. Both Song et al. [1] and lismaa et al. [10] mapped this receptor to $1 \mathrm{p} 34.3-\mathrm{p} 36.1$.

GPR3 mRNA is broadly expressed in neurons in various brain regions, including the cortex, thalamus, hypothalamus, amygdala, hippocampus, pituitary, and cerebellum [10-13]. Notably, the GPR3 protein is overexpressed in neurons in post-mortem brain tissue sections from individuals afflicted by Alzheimer's disease [14]. GPR3 mRNA is also expressed in the eye, lung, kidney, liver, testes, and ovary, among other tissues [10-13].

\section{G protein-coupled receptor 6}

GPR6 was first cloned from a rat CDNA library in 1994 and named rCNL3 [15]. This was followed by its cloning from human genomic DNA in 1995 [1, 16]. Song et al. [1] localized GPR6 to chromosomal region $6 \mathrm{q} 21$, and Heiber et al. [16]. specified that its chromosomal localization is $6 q 21-22.1$. GPR6 mRNA is predominantly expressed in neurons in the brain, particularly in the striatum (caudate, putamen, nucleus accumbens, and olfactory tubercle). It is also located in the frontal cortex, retrosplenial cortex, hippocampus, amygdala, and hypothalamus to a lesser extent $[15,16]$.

Peripheral expression of GPR6 is apparently low. Song et al. [15] did not detect GPR6 mRNA in the heart, spleen, lung, liver, muscle, kidney, or testis in rats. However, Ignatov et al. [17] were able to detect relatively low levels of GPR6 mRNA in the testis and skeletal muscle in mice.

${ }^{1}$ Department of Pharmacology and Toxicology, University of Louisville School of Medicine, Louisville, KY 40292, USA

Correspondence: Zhao-Hui Song (zhsong@louisville.edu)

Received: 15 January 2018 Accepted: 17 April 2018

Published online: 25 June 2018 
GPR3, 6, and 12 as novel molecular targets for cannabidiol

Table 1. Signaling pathways of GPR3, GPR6, and GPR12

\begin{tabular}{|c|c|c|c|}
\hline $\begin{array}{l}\text { Signaling } \\
\text { pathway }\end{array}$ & GPR3 & GPR6 & GPR12 \\
\hline \multicolumn{4}{|l|}{$G$ protein } \\
\hline$G_{i}$ & $\begin{array}{l}\text { Constitutively active [20] } \\
\text { PTX treatment } \uparrow A C \text { activation [20] } \\
\mathrm{G}_{\alpha i} \text { overexpression } \downarrow \text { cAMP [20] } \\
\text { No effect on cAMP reporter after forskolin } \\
\text { stimulation [22] }\end{array}$ & $\begin{array}{l}\text { Constitutively active [20] } \\
\text { PTX treatment } \uparrow A C \text { activation [20] } \\
\mathrm{G}_{\text {oi }} \text { overexpression } \downarrow \text { cAMP [20] } \\
\text { PTX treatment } \downarrow \text { ligand-induced } \mathrm{Ca}^{2+} \\
\text { mobilization [17] } \\
\downarrow \text { cAMP reporter after forskolin stimulation } \\
{[22]}\end{array}$ & $\begin{array}{l}\text { Constitutively active [22] } \\
\downarrow \text { cAMP reporter after forskolin } \\
\text { stimulation [22] } \\
\text { PTX treatment } \downarrow \text { ligand-induced } \\
\text { GIRK currents [19] }\end{array}$ \\
\hline \multicolumn{4}{|l|}{ Non-G protein } \\
\hline ERK1/2 pathway & Signals via ERK1/2 and Akt [23] & $\begin{array}{l}\text { Signals via ERK } 1 / 2 \text { and sphingosine kinase } \\
\text { phosphorylation [17] }\end{array}$ & Signals via ERK1/2 [24] \\
\hline
\end{tabular}

G protein-coupled receptor 12

GPR12 was originally isolated from a rat CDNA library in 1991 and named R334 [18]. Two years later, it was isolated from a mouse cDNA library and re-named GPCR01 [8]. The receptor was ultimately cloned from a human genomic DNA library in 1995 and mapped to chromosomal region $13 q 12$ [1].

GPR12 mRNA was originally identified in the pituitary gland [18]. In the brain, the transcript is expressed in neurons in the frontal cortex, piriform cortex, thalamus, hypothalamus, hippocampus, amygdala, and olfactory bulb. Peripherally, GPR12 mRNA is found in the testis and oocytes $[8,13,18,19]$.

\section{SIGNALING PATHWAYS}

Numerous groups have studied GPR3, GPR6, and GPR12 either individually or concurrently with regard to their coupling possibilities (Table 1). In this section, we have divided subsections by cell signaling pathway, rather than receptors, for cohesiveness.

$\mathrm{G}_{\mathrm{s}}$ protein

GPR3 was first described as a constitutive activator of adenylate cyclase by Eggerickx et al. in 1995 [11]. They found that GPR3 activates adenylate cyclase as measured by cAMP accumulation; the level of activation was comparable to that of other ligandactivated, $\mathrm{G}_{\mathrm{s}}$-coupled receptors. The authors further determined that this result was not due to a mutation of the receptor and was independent of species or cell type [11]. The group hypothesized that this constitutive activity could be due to stimulation by a ubiquitous ligand that may be free, membrane-bound, or membrane-derived. Alternatively, they propose that this could also be due to basal $G_{s}$ coupling. Various groups have since supported this initial finding of GPR3 constitutive activation and have proceeded to show similar $\mathrm{G}_{\mathrm{s}}$ activity in GPR6 and GPR12 [20-22].

Notably in 2002, Uhlenbrock et al. [20] showed that GPR3, GPR6, and GPR12 constitutive activity occurred in the presence of medium prepared with serum. When the cells were serum starved, the constitutive activity was reduced, potentially suggesting the involvement of an endogenous ligand.

Bresnick et al. [21] sought to identify the signal transduction pathways used by various orphan GPCRs, including GPR3 and GPR12. They used cAMP response element- $\beta$-lactamase-as a CAMP reporter to study orphan receptors transfected into human embryonic kidney 293 (HEK293) cells. The results showed that both GPR3 and GPR12 activated a $\mathrm{G}_{\mathrm{s}}$ pathway since an increase of $\beta$-lactamase activity was observed after transfection with the respective receptor. GPR6 was not tested by this lab.

Martin et al. [22] studied GPR3, GPR6, and GPR12 concurrently in 2015 and provided further evidence of constitutive activity at these receptors. Using Chinese hamster ovary ( $\mathrm{CHO}$ ) cells cotransfected with a CRE-luciferase reporter and one of the three orphan receptor genes, they observed that CAMP signaling was constitutively stimulated. For each receptor, the constitutive stimulation observed was reported as being $>200 \%$ stimulation above the baseline, which was their defined cutoff for constitutive activity.

\section{$\mathrm{G}_{\mathrm{i} / \mathrm{o}}$ protein}

Some of the aforementioned groups studying the coupling to the $G_{s}$ protein also studied $G_{i}$ in parallel. Using HEK293 cells transfected with either GPR3, GPR6, or GPR12, Uhlenbrock et al. [20] concluded that all three receptors constitutively activated $G_{i}$ as well. They demonstrated that adenylate cyclase stimulation was enhanced following treatment with pertussis toxin. Furthermore, overexpression of $G_{i}$ reduced the cAMP levels stimulated by GPR3, GPR6, and GPR12. Since the signaling was enhanced upon $G_{i}$ inhibition by pertussis and inhibited upon $G_{i}$ overexpression, the data suggest that the three receptors couple to $G_{i}[20]$.

Martin et al. [22] took a different approach to measuring $G_{i}$ activity. Cells were co-transfected with the GPR3/6/12 and CREluciferase reporters. Forskolin stimulation maximally stimulates CAMP production such that $\mathrm{G}_{\mathrm{s}}$-mediated production is nonsignificant and any constitutive coupling to $G_{i}$ becomes apparent by inhibition of CAMP signaling. Constitutive inhibition of 
adenylate cyclase activity was defined as a $40 \%$ decrease below the forskolin baseline. It is worth noting that while the authors showed that GPR6 and GPR12 expression led to a decrease in CREluciferase reporter expression, they observed that GPR3 did not constitutively inhibit forskolin-stimulated CAMP. These findings somewhat contradict those of the previously mentioned group [20] that found that GPR3 constitutively activated $G_{i}$.

Ignatov et al. [17] also conducted studies using pertussis toxin to inhibit $G_{i}$ but focused specifically on GPR6. They observed a suppression of ligand-induced $\mathrm{Ca}^{2+}$ mobilization in $\mathrm{CHO}$ cells overexpressing GPR6 following treatment of pertussis toxin, which suggests the role of $\mathrm{G}_{\mathrm{i} / \mathrm{o}}$ in GPR6-mediated $\mathrm{Ca}^{2+}$ mobilization. In addition, Ignatov et al. [19] suggested that GPR12 couples to $G_{i / o}$ because ligand-induced $G$ protein-activated inwardly rectifying $\mathrm{K}^{+}$ currents were blocked by pertussis toxin in Xenopus oocytes.

\section{Non-G proteins}

Tanaka et al. [23] demonstrated that GPR3 acts through extracellular signal-regulated kinase $1 / 2$ (ERK1/2) and protein kinase B (Akt) signaling to mediate anti-apoptotic effects. By downregulating GPR3 in cerebellar granule neurons, the levels of ERK and Akt phosphorylation were reduced. This group also discovered that by adding a protein kinase A (PKA), ERK1/2, or phosphatidylinositol-3-kinase (PI3) inhibitor, the anti-apoptotic effect of GPR3 could be blocked.

In contrast, Ignatov et al. [17] showed that GPR6 inhibits apoptotic cell death through a mechanism that relies on activation of sphingosine kinase in addition to ERK1/2 phosphorylation. In PC12 cells, GPR12 activated the ERK1/2 signaling pathway and caused a consequential increase in the expression of $\mathrm{Bcl}-2, \mathrm{Bcl}-\mathrm{xl}$, and SYP [24].

Lowther et al. [25] showed that GPR3 signals at the level of the plasma membrane and undergoes desensitization and internalization through mechanisms involving GPCR-regulated kinase 2 and $\beta$-arrestin2.

A group studying Alzheimer's disease determined that GPR3 expression modulates amyloid $\beta(A \beta)$ production through $\beta$ arrestin2 [26]. Neither GPR6 nor GPR12 were included in this study. Overexpression of $\beta$-arrestin 2 increased $A \beta$ production, whereas silencing it decreased $A \beta$ production. GPR3 is critical for this process, as evidenced by the fact that elevation of $A \beta$ by overexpression of $\beta$-arrestin2 only occurred when GPR3 was also expressed [26].

Nelson and Sheng [27] studied the GPR3- $\beta$-arrestin2 interaction by mutating the receptor. Through truncation of the $\mathrm{C}$-terminal tail-the location at which $\beta$-arrestin2 interacts with GPR3-A $\beta$ production and colocalization of GPR3 and amyloid precursor protein (APP) were decreased. It is clear from these results that $\beta$ arrestin2 is the key for the interaction between GPR3 and APP, which led to enhanced $A \beta$ production [27].

Yin et al. [28] used the $\beta$-arrestin2 PathHunter assay system to measure $\beta$-arrestin2 recruitment in HEK293 cells transiently transfected with GPR3, GPR6, and GPR12. However, they found no ligand-induced $\beta$-arrestin2 recruitment through these receptors when testing any of the previously reported agonists for these receptors.

\section{POTENTIAL LIGANDS}

G protein-coupled receptor 3

S1P and dihydrosphingosine 1-phosphate were first demonstrated to be agonists of GPR3 by the lab of Uhlenbrock et al. [20], as activation by these ligands increased the CAMP concentration in GPR3-transfected cells. However, this claim has been challenged by several groups, who could not reproduce the results using these lysophospholipid ligands [14, 28, 29].

Diphenyleneiodonium chloride (DPI) is another proposed agonist for GPR3 [30]. In HEK293 cells stably expressing GPR3,
DPI stimulated numerous signaling pathways, including $\mathrm{Ca}^{2+}$ mobilization, cAMP accumulation, $\beta$-arrestin2 recruitment, and receptor internalization. In comparison, the putative agonist S1P failed to induce either $\beta$-arrestin2 recruitment or CAMP accumulation in cells stably expressing GPR3.

In addition, an inverse agonist has also been identified for GPR3 [31]. AF64394 and its analogs were shown to reduce cAMP accumulation. AF64394, though, had the most pronounced effect out of the set of compounds tested, with a reported $\mathrm{plC}_{50}$ of 7.3.

\section{G protein-coupled receptor 6}

Both Uhlenbrock et al. [20] and Ignatov et al. [17] identified S1P as a ligand for GPR6 using calcium mobilization assays, which showed S1P-induced and GPR6-mediated intracellular calcium release. Conflictingly, Yin et al. [28] did not detect any S1Pagonism activity for GPR6 when using the $\beta$-arrestin2 PathHunter assay and thus concluded that GPR6 remains an orphan receptor.

\section{G protein-coupled receptor 12}

With the use of a calcium mobilization assay, Uhlenbrock et al. [20] proposed that S1P is a ligand for GPR12. More importantly, Ignatov et al. [19] then showed that sphingosylphosphorylcholine (SPC) had higher affinity than S1P for GPR12. The same lab that refuted the notion that lysophospholipids are ligands for GPR3 and GPR6 likewise reported that GPR12 did not respond to either S1P or SPC in their $\beta$-arrestin2 recruitment experiments [28].

In addition to these studies on S1P and SPC, reports have also been published on several other potential and unique ligands for GPR12. Lin et al. [32] studied a set of 15 different compounds isolated from endophytic Streptomyces sp. and found tyrosol to be the only ligand that promoted a significant increase in CAMP in both the CHO and HEK293 cells transfected with GPR12. In a separate study, the same laboratory isolated 4-(hydroxymethyl)-5hydroxy-2H-pyran-2-one from the marine-derived fungus Aspergillus flavus and found that the compound stimulates CAMP production in cells transfected with GPR12 in a concentrationdependent manner [33]. In a similar vein, Du et al. [34] isolated and characterized various compounds from Penicillium citrinum, a volcanic ash-derived fungus, five of which induced CAMP production in $\mathrm{CHO}$ cells transfected with GPR12 at a concentration of $10 \mu \mathrm{M}$.

\section{PHYSIOLOGICAL/PATHOLOGICAL IMPORTANCE}

\section{GPR3: neurite outgrowth/neuronal cell survival}

Neurite is a general term for any projection off of a neuron and includes dendrites and axons. In 2007, Tanaka et al. [35] showed that overexpression of the GPR3 receptor enhanced the neurite outgrowth of cerebellar granule neurons (Table 2). In contrast, knockdown of GPR3 resulted in a reduction of neurite outgrowth. Interestingly, neurite outgrowth in receptor knockout mice could be rescued by either GPR3 or GPR12 expression. Additionally, the authors showed that GPR3 is endogenously enhanced in developing rat cerebellar granule neurons, which they suspect is important for development [35].

Tanaka et al. [36] also demonstrated that endogenous GPR3 expression in rat cerebellar neurons was anti-proliferative because its knockdown via small interfering RNA (siRNA) enhanced proliferation, whereas exogenous GPR3 expression partially antagonized proliferation. Exogenous GPR3 expression also correlated with an increase in p27/kip, which promotes mitotic exit and is another key regulator of proliferation in the developing cerebellum. In contrast, GPR3 knockdown decreased p27/kip expression. Using cell cycle kinetic studies, the authors further showed that GPR3 arrests the cell cycle at $G_{1}$ [36].

This group continued their research on GPR3 in cerebellar granule neurons and found that GPR3 is also important for neuronal cell survival. The cerebellar granule neurons of GPR3 
GPR3, 6, and 12 as novel molecular targets for cannabidiol

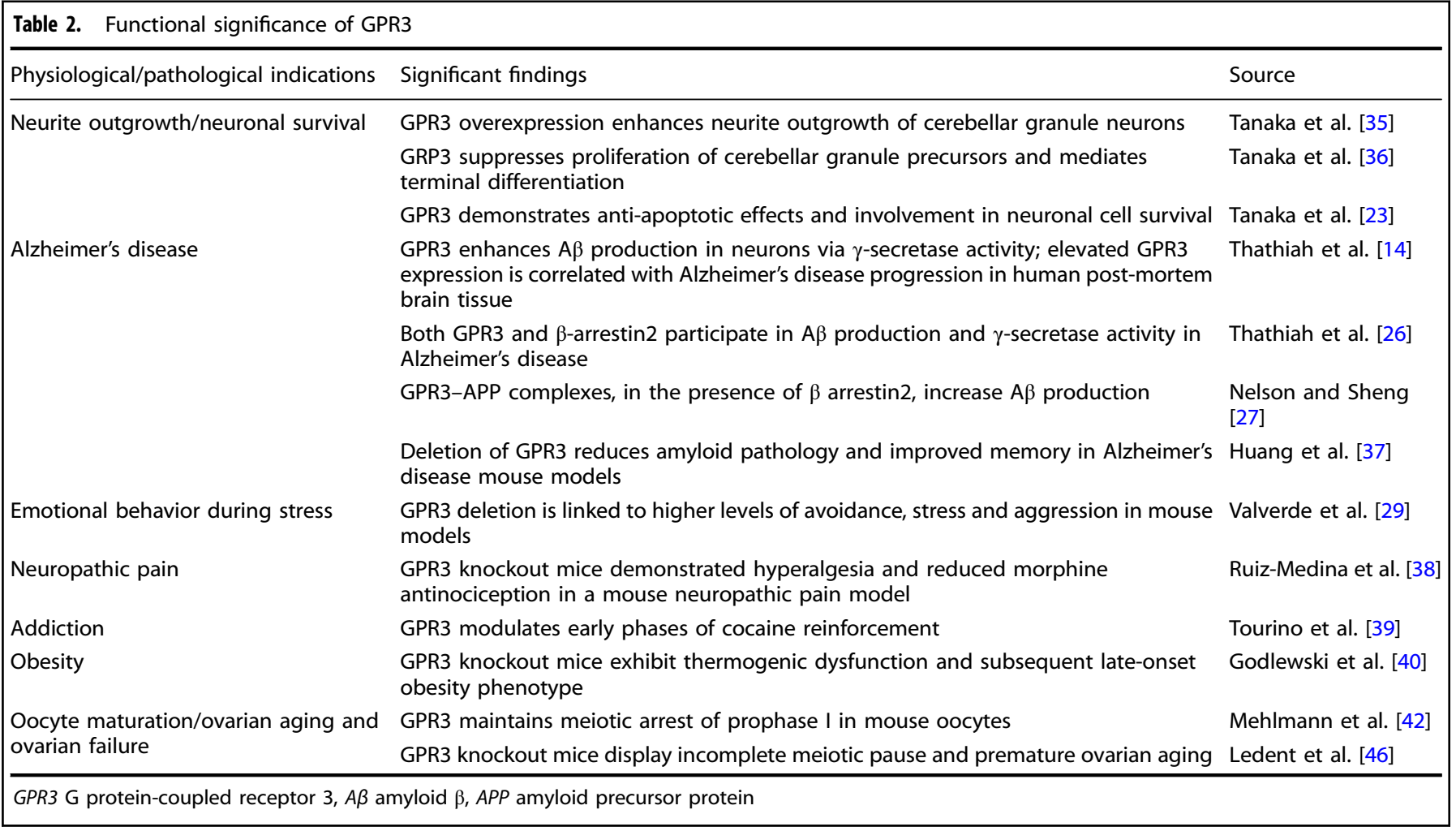

knockout mice exhibited decreased survival in vitro compared to wild-type mice [23]. Brain sections from these mice also exhibited an increased number of caspase 3-positive neurons in the internal granular layer compared with wild-type mice. In terms of signaling, knockdown of endogenous GPR3 inhibits ERK and Akt phosphorylation under normal culture conditions. Inhibition of PKA, MAPK, or PI3 kinase eliminated the GPR3-mediated antiapoptotic effect. Lastly, GPR3 knockout mice exhibited a larger infarct compared to wild-type mice in a model of brain ischemia [23].

GPR3: Alzheimer's disease

Alzheimer's disease is a neurodegenerative disease with two distinct hallmarks: amyloid plaque formation and neurofibrillary tangles consisting of hyperphosphorylated tau. The first hallmark, amyloid plaques, are produced from accumulation of $A \beta$ proteins. Cleavage of APP by $\gamma$-secretase generates $A \beta$. The major species of amyloid protein synthesized from this cleavage are $A \beta 40$ and $A \beta 42$, with $A \beta 42$ being the more fibrogenic species of the two. GPR3 has been identified as a mediator of $A \beta$ production by two independent groups [14, 26, 27, 37].

Thathiah et al. [14] demonstrated that GPR3 increases $\gamma^{-}$ secretase activity in vitro by co-transducing hippocampal neuronal cells with a direct substrate for $\gamma$-secretase that produces A $\beta$ (APPC99) and GPR3. By immunoblotting cell membrane extracts from HEK293 cells transfected with GPR3, the authors have shown that GPR3 increases cell surface localization of $y$-secretase subunits. In an Alzheimer's disease cell culture model, overexpression of GPR3 increased $A \beta$ secretion, while ablation of GPR3 using siRNA decreased the amount of $A \beta$ produced. Furthermore, they demonstrated that GPR3 is highly expressed in the normal human brain, specifically in areas implicated in Alzheimer's disease, and can then become overexpressed in the sporadic Alzheimer's disease brain.

Using co-immunoprecipitation methods, this same group later showed that $\beta$-arrestin2 interacts with the Aph-1a subunit of the $\gamma$-secretase complex [26]. In addition, they demonstrated that downregulation of $\beta$-arrestin2 by siRNA in HEK-APP695 cells, as well as $\beta$-arrestin2 knockout in mice, led to a reduction in accumulation of the APP C-terminal fragments $A \beta 40$ and $A \beta 42$. This outcome is similar to the result produced by an inhibitor of $\gamma^{-}$ secretase. Moreover, the authors demonstrated that $\beta$-arrestin2 expression was high in Alzheimer's disease patients' post-mortem brain and that overexpression of $\beta$-arrestin2 increased $A \beta$ generation.

The same group, Huang et al. [37], later studied the importance of GPR3 in four different Alzheimer's disease transgenic mouse models. In all four of the models used, GPR3 knockout reduced amyloid pathology and improved memory. The group also showed improved memory in GPR3 knockout/Alzheimer's disease model mice.

In 2013, Nelson and Sheng [27] demonstrated that GPR3 is capable of complexing with APP, an interaction that is made possible by $\beta$-arrestin2. They observed that $\beta$-arrestin2 alone failed to increase $A \beta$ production in vitro in HEK293 cells transfected with APP. Only after additional transfection with GPR3 was there an increase in $A \beta$ production. $\beta$-Arrestin 2 is important nonetheless, as siRNA knockdown of $\beta$-arrestin2 lowered the $A \beta$ produced in GPR3-transfected cells. In addition, Nelson and Sheng [27] showed that GPR3 co-localizes with endogenous APP in clusters and that $\beta$-arrestin2 also partially co-localizes with GPR3 in mature rat hippocampal neurons. Furthermore, GPR3 increases the processing of APP, and the amount of $A \beta$ produced correlates with the amount of GPR3-APP binding.

\section{GPR3: emotional behavior}

GPR3 has been shown to modulate anxiety-related behavioral responses. Valverde et al. [29] showed that GPR3 knockout mice displayed increased levels of avoidance to novel and unfamiliar environments compared to wild-type mice. This avoidance was associated with increased reactivity to stress in behavioral despair paradigms and to aggression in resident-intruder models. The 
Table 3. Functional significance of GPR6

\begin{tabular}{|c|c|c|}
\hline $\begin{array}{l}\text { Physiological/pathological } \\
\text { indications }\end{array}$ & Significant findings & Source \\
\hline Neurite outgrowth & GPR6 overexpression increases neurite outgrowth of cerebellar granule neurons & Tanaka et al. [35] \\
\hline Alzheimer's disease & $\begin{array}{l}\text { GPR6 can be upregulated via a C1q-mediated method; GPR6 is crucial for the C1q-mediated } \\
\text { neuroprotection against } A \beta \text {-induced neurotoxicity }\end{array}$ & Benoit et al. [49] \\
\hline Parkinson's disease & $\begin{array}{l}\text { GPR6-deficient mice show increased striatal dopamine and reduced dyskinesia in a Parkinson's } \\
\text { disease model }\end{array}$ & Oeckl et al. [50] \\
\hline Instrumental learning & $\begin{array}{l}\text { GPR6 regulates CAMP production in striatal medium spiny neurons, and is involved in } \\
\text { instrumental conditioning }\end{array}$ & Lobo et al. [51] \\
\hline
\end{tabular}

authors determined that the reduced ability of GPR3 knockout mice to cope with stress was not due to changes in the hypothalamic-pituitary-adrenal axis since corticosterone levels were normal when the mice were exposed to unfamiliar environments. They did, however, observe changes in monoamine neurotransmission in the hippocampus, hypothalamus, and forebrain of GPR3 knockout mice.

GPR3: neuropathic pain

Ruiz-Medina et al. [38] studied the involvement of GPR3 in neuropathic pain after a spinal cord injury in mice. GPR3 knockout mice demonstrated hyperalgesia compared to wild-type mice. Knockout mice also had reduced morphine antinociception, highlighting the importance of GPR3 in relieving neuropathic pain. There were no differences, however, in mechanical allodynia; microglia and astrocyte activation in the ipsilateral dorsal horn was comparable in both phenotypes, and thus the inflammatory response was unaltered by the presence or absence of GPR3.

\section{GPR3: addiction}

Tourino et al. [39] showed that GPR3 modulates the early phases of cocaine reinforcement. GPR3 knockout mice exhibited increased responses to reward from cocaine, self-administered more cocaine, and had increased locomotor activity compared to wild-type control mice. Taken together, the authors suggested that the enhanced responsiveness in the early phases of reinforcement implicates GPR3 in developing addiction.

\section{GPR3: obesity}

GPR3 is purported to be important for age-related obesity [40]. Mice lacking GPR3 exhibited normal weights for the first 5 months, before subsequently gaining excess weight. Heterozygous and homozygous knockout mice gained significantly more weight than their age-matched wild-type GPR3 littermates. Furthermore, GPR3 knockout mice displayed increased fat droplet accumulation, increased triglyceride content in the liver, and increased concentrations of leptin, all of which correlate with the increased adiposity. GPR3 knockout mice also had decreased energy expenditure and decreased core body temperature, as well as a decrease in several markers for thermogenesis [40].

GPR3: oocyte maturation/ovarian aging and ovarian failure Prior to ovulation, oocytes are arrested in prophase I of meiosis. During ovulation, upon release of luteinizing hormone (LH), oocytes resume meiosis and undergo maturation. High levels of cAMP stimulated by $\mathrm{G}_{\mathrm{s}}$ activation of adenylyl cyclase are required to maintain meiotic arrest, whereas LH stimulation and reduction in cAMP levels are required for meiotic resumption [41]. GPR3 was first identified as pivotal for oocyte meiosis in 2004, when Mehlmann et al. [42] found that GPR3, which is localized to the oocyte, maintains the prophase I arrest in mice. GPR3 knockout mouse oocytes were able to resume meiosis within antral follicles. Since its discovery, many independent groups have confirmed the role of GPR3 in oocyte maturation in many species, including mice, rats, frogs, pigs, and humans [12, 42-45].

Ledent et al. [46] compared young vs. aged GPR3 knockout mice to determine if age affected fertility when GPR3 is absent. Young GPR3 knockout mice were fertile, although they had progressively smaller litter sizes. In contrast, aged mice lacking the receptor suffered severe infertility, as embryos did not develop and fragmented oocytes presented after superovulation. Ledent et al. [46] thus concluded that GPR3 protects and possibly rescues oocytes from aging.

GPR6: neurite outgrowth/neuronal cell survival

The dependence of neurite outgrowth on CAMP was demonstrated by Cai et al. [47]. GPR6, similar to GPR3 and GPR12, increases neurite outgrowth when overexpressed in rat cerebellar granule neurons (Table 3) [35]. These results strongly indicate that GPR6, as well as GPR3 and GPR12, is critical for neurite outgrowth due to its constitutive activity to produce CAMP.

\section{GPR6: Alzheimer's disease}

Individuals with Alzheimer's disease have been found to produce $\mathrm{C} 1 \mathrm{q}$, a protein that binds $\mathrm{A} \beta$ plaques and aids in the clearance of the plaques while also promoting a damaging inflammatory response [48]. Benoit et al. [49] found that, through a C1qmediated mechanism, GPR6 is upregulated in Alzheimer's disease mouse models. They also showed that GPR6 is crucial for the C1qmediated neuroprotection against $A \beta$-induced neurotoxicity in the mouse model. As such, GPR6 may play a key role in neuroprotection in individuals with Alzheimer's disease [49].

\section{GPR6: Parkinson's disease}

GPR6 also has implications in Parkinson's disease. GPR6-deficient mice have increased dopamine concentrations in striatal tissue, decreased CAMP concentrations in intact mouse striatum, and improved motor activity along with decreased abnormal movements in the mouse dyskinesia model of Parkinson's disease [50]. This research highlighting GPR6 as a possible target for Parkinson's disease treatment is distinctly novel from dopaminecentric therapeutics. An antagonist for GPR6 could thus present as a therapeutic agent for Parkinson's disease.

GPR6: instrumental learning

The striatum is a key brain structure for integrating information from the cortex to substantia nigra. Lobo et al. [51] found that GPR6 is essential for the regulation of cAMP production in striatal medium spiny neurons in vitro, based on the observation that CAMP was reduced in GPR6 knockout neurons. In addition, GPR6 knockout mice demonstrated selective changes in instrumental conditioning. This work suggests that GPR6 is likely crucial for 
GPR3, 6, and 12 as novel molecular targets for cannabidiol

Table 4. Functional significance of GPR12

\begin{tabular}{|c|c|c|}
\hline $\begin{array}{l}\text { Physiological/pathological } \\
\text { indications }\end{array}$ & Significant findings & Source \\
\hline \multirow[t]{3}{*}{$\begin{array}{l}\text { Neurite outgrowth/neuronal } \\
\text { survival }\end{array}$} & $\begin{array}{l}\text { SPC interacts with GPR } 12 \text { and promotes the proliferation of neuronal precursor cells and the } \\
\text { maturation of post-mitotic neurons }\end{array}$ & Ignatov et al. [19] \\
\hline & GPR12 overexpression promotes neurite outgrowth & Tanaka et al. [35] \\
\hline & GPR12 initiates neurite outgrowth in PC12 cells & Lu et al [24] \\
\hline Obesity and metabolic disorders & GPR12 knockout mice display increased dyslipidemia and obesity & Bjursell et al. [53] \\
\hline Cell survival and proliferation & GPR12 enhances cell proliferation and survival in HEK293 cells & Lu et al. [54] \\
\hline Cancer & $\begin{array}{l}\text { GPR12 promotes keratin } 8 \text { phosphorylation and reorganization, reducing cancer cell } \\
\text { viscoelasticity }\end{array}$ & Park et al. [56] \\
\hline
\end{tabular}

normal learning processes, as well as a potential target for treatment of neuropsychiatric disorders.

GPR12: neurite outgrowth and neuronal development

The lab of Ignatov et al. [19]. showed that the lysophospholipid SPC is a high-affinity ligand for GPR12 (Table 4). By in situ hybridization on embryonic and adult mouse brains, they determined that GPR12 transcripts were present in the embryonic brain with a high concentration in areas of neuronal differentiation. In adult mouse brains, GPR12 was identified in the limbic system. In vitro cell culture revealed that embryonic cerebral cortical neurons had increased synaptic contacts following SPC treatment, and HT22 hippocampal cells exhibited increased cell proliferation and clustering in response to SPC. These results led the lab to conclude that by interacting with GPR12, SPC can positively influence the proliferation of neuronal precursor cells and the differentiation and maturation process of post-mitotic neurons.

As with GPR3 and GPR6, Tanaka et al. [35] showed that GPR12 overexpression also increased neurite outgrowth. In fact, GPR12mediated outgrowth was the most prominent of the three receptors. They further showed that the action of GPR12 on neurite outgrowth depends on the $G_{s}$ protein and CAMPdependent protein kinase. In experiments in which GPR3 was knocked down, GPR12 also rescued neurite outgrowth. However, similar to GPR6, GPR12 exhibits low expression in rat cerebellar granule neurons [35, 36, 52].

In 2012, Lu et al. [24] demonstrated that GPR12 induces neurite outgrowth in PC12 cells. The consequences of GPR12 overexpression on PC12 cells were studied by transfecting PC12 cells with recombinant human GPR12. The authors showed that GPR12 overexpression instigated the differentiation of PC12 cells into neuron-like cells with increased size of the cell and neurite generation. The researchers proposed that a possible mechanism for this phenotype is the activation of ERK $1 / 2$ signaling and a substantial increase in the expression of multiple genes related to neurite outgrowth.

GPR12: obesity and metabolic disorders

Bjursell et al. [53] investigated the importance of GPR12 in metabolism. They found that food intake was not significantly affected in GPR12 knockout mice compared to wild-type mice. However, the GPR12 knockout mice exhibited increased body weight and body fat mass, decreased respiratory exchange ratio, hepatic steatosis, and dyslipidemia. The authors concluded that GPR12 plays a significant role in energy balance, which is supported by the fact that GPR12 knockout mice developed obesity and decreased energy expenditure.

GPR12: oocyte maturation

Hinckley et al. [13] studied GPR12 expression and its role in oocyte meiotic arrest. GPR12 mRNA is expressed in both rat and mouse oocytes. They demonstrated that GPR12 expression in oocytes prevents meiotic maturation, whereas downregulation of GPR12 allows meiotic resumption. Stimulating oocytes with the putative ligands S1P and SPC led to maturation. It appears from their findings that GPR12 is important for the maintenance of meiotic arrest in oocytes.

GPR12: cell survival and proliferation

Lu et al. [54] demonstrated that GPR12 regulates cell proliferation and survival in HEK293 cells. Upon overexpression of GPR12, cell proliferation increased and cell survival was enhanced under serum deprivation conditions. Furthermore, when GPR12 was overexpressed, the authors found activation of extracellular signal-regulated protein kinase signaling, increased total ERK1/2, and increased B cell lymphoma/ leukemia-2 expression.

GPR12: cancer

Keratin 8 (K8) is involved in cancer cell migration and invasion by changing the viscoelasticity of cancer cells [55]. Park et al. [56] showed that overexpression of GPR12 induces K8 phosphorylation and reorganization, and silencing of the receptor reduces both of these K8 processes. These data indicate that GPR12 may be a potential target for prevention of metastasis by developing compounds that can block GPR12.

\section{NOVEL MOLECULAR TARGETS FOR CBD}

GPR3, GPR6, and GPR12 are considered orphan receptors because their endogenous agonists have yet to be confirmed. However, these orphan receptors share $35 \%$ amino acid sequence identity in the transmembrane regions with the $C B 1$ and $C B 2$ cannabinoid receptors [57]. Because GPR3, GPR6, and GPR12 are phylogenetically related to cannabinoid receptors, we recently tested various classes of cannabinoids for their potential effects on these three orphan receptors.

We first sought to confirm the constitutive activity of GPR3, GPR6, and GPR12. Our data showed that all three receptors were constitutively active $[6,7]$. Subsequently, we tested the effects of cannabinoids on GPR3-mediated and GPR6-mediated $\beta$ - 
306

arrestin2 recruitment, and GPR12-mediated CAMP accumulation.

We tested two well-established endocannabinoids, 2arachidonoyl glycerol and anandamide, as well as two putative cannabinoids, noladin ether and virodhamine. Of the four, none had any significant effect on $\beta$-arrestin2 recruitment to either GPR3 or GPR6. Similarly, in cells expressing GPR12, none of the endocannabinoids tested altered CAMP accumulation up to 100 $\mu \mathrm{M}$.

We also tested five phytocannabinoids: $\Delta^{9}$-tetrahydrocannabinol $\left(\Delta^{9}-\mathrm{THC}\right), \mathrm{CBD}$, cannabinol, cannabigerol, and cannabichromene. The majority of phytocannabinoids tested showed no significant effect on $\beta$-arrestin2 recruitment to either GPR3 or GPR6; CBD, being the exception, concentration dependently reduced $\beta$-arrestin2 recruitment to both GPR3 and GPR6 [6]. We also found that CBD exhibited higher potency for GPR6 than for GPR3 [6]. With regard to GPR12, most of the phytocannabinoids tested had no effect up to $100 \mu \mathrm{M}$, again with the exception of CBD, which significantly decreased CAMP accumulation concentration dependently with an $\mathrm{EC}_{50}$ of approximately $10 \mu \mathrm{M}$ [7]. Together, these results demonstrate for the first time that GPR3, GPR6, and GPR12 are novel molecular targets for CBD, and CBD is a new inverse agonist for this family of orphan receptors $[6,7]$.

Building on this discovery, we next conducted a structure-activity relationship analysis of CBD as an inverse agonist of GPR3, GPR6, and GPR12. We designed the study around $\mathrm{CBD}$ analogs, with changes made to either the aliphatic side chain or the free hydroxyl groups. Cannabidivarin exchanges the pentyl for a propyl side chain, and 0-1821 substitutes the pentyl for a methyl side chain. In contrast, CBD-2',6'-dimethyl ether contains the same pentyl side chain but substitutes the $2^{\prime}, 6^{\prime}$ hydroxyl groups with methoxyl groups. Our data showed all three derivatives to be less potent than the original structure of CBD. Thus, these data demonstrate that both the pentyl side chain and the free hydroxyl groups are important for the inverse agonism of CBD on GPR3, GPR6, and GPR12 [5, 7]. Despite the finding of CBD action on these receptors, GPR3, GPR6, and GPR12 remain orphans since, by definition, they do not have a confirmed endogenous ligand. It is possible that by binding to the receptor, CBD is blocking the effects of unidentified, endogenous agonists and is therefore a neutral antagonist, rather than an inverse agonist for GPR3, GPR6, or GPR12. While we acknowledge this possibility, we believe that it is unlikely for the following two reasons. First, the original findings of S1P/SPC agonism on these orphan receptors have been challenged by a number of independent groups, who could not reproduce the reported results of S1P/SPC agonism $[14,28,29]$. Second, in our hands neither serum deprivation nor charcoal-stripped serum affected either the constitutive activity of these orphan receptors or the $C B D$-induced reduction of constitutive activity. Based on these two reasons, we believe that CBD is truly an inverse agonist on GPR3, GPR6, and GPR12.

\section{SIGNIFICANCE AND IMPLICATIONS}

CBD is one of the major components of marijuana [58,59]. Unlike $\Delta^{9}-\mathrm{THC}$, the major psychoactive constituent of cannabis, CBD is a non-psychotropic phytocannabinoid [58, 59]. CBD has been proposed to act on many targets, including enzymes and receptors. For example, CBD has been shown to act, with low affinity, on a variety of GPCRs. CBD has low affinity for CB1 and CB2 [60], but Pertwee [61] showed that it was able to antagonize the effect of CB1 agonists indirectly. Laprarie et al. [62]. supported this finding when they identified $C B D$ as a negative allosteric regulator of $\mathrm{CB} 1$. In addition, $\mathrm{CBD}$ has been demonstrated to be an agonist at serotonin $5 \mathrm{HT}_{1 \mathrm{a}}[63,64]$ and $5 \mathrm{HT}_{3 \mathrm{a}}[65]$ receptors, an antagonist at GPR55 [66], and an allosteric modulator of the mu and delta opioid receptors [67]. Other than working on GPCRs, CBD has also been identified to work as a PPAR- $\gamma$ agonist, a TRPM 8 antagonist, an $a_{1}$ and $a_{3}$ glycine receptor agonist, an agonist for TRPV1 and TRPV2 channels, and a TRPA1 antagonist [68].

The discovery that GPR3, GPR6, and GPR12 are novel targets for $C B D$ occurred very recently. While $C B D$ has many reported targets, the recent discovery of GPR3, GPR6, and GPR12 as novel targets of $C B D$ provides a new perspective on the potential therapeutic effects of $C B D$ and warrants further study. Considering the above reviewed involvements of GPR3, GPR6, and GPR12 in Alzheimer's disease, Parkinson's disease, cancer, and infertility, it is especially worthwhile to study whether these receptors are involved in the potential effects of CBD in these therapeutic areas, using animal models lacking these receptors.

CBD is not a potent ligand for GPR3 $\left(\mathrm{EC}_{50} \sim 1 \mu \mathrm{M}\right)$ and GPR6 $\left(\mathrm{EC}_{50}\right.$ $\sim 100 \mathrm{nM}$ ) in the $\beta$-arrestin2 recruitment assay [6]. Additionally, it is not a potent ligand for GPR12-mediated CAMP accumulation (EC $C_{50}$ $\sim 10 \mu \mathrm{M})$ [7]. Nevertheless, CBD still provides a molecular scaffold upon which structural changes can be made to develop new, potentially more potent and efficacious ligands for GPR3, GPR6, and GPR12.

Our collaborators, Morales et al. [3] have recently developed an in silico model of GPR3. In developing the model, they hope to gain insight into the structure and function of GPR3 and use the model as a powerful tool for the development of high-affinity/ potency ligands for the receptor. Based on our experimental data of $C B D$ as an inverse agonist, as well as our CBD structure-activity relationship data (i.e., modifications to the aliphatic side chain and free hydroxyl groups), CBD and its analogs can be docked within the GPR3 model. From docking, chemical modifications to the CBD scaffold can be designed, novel ligands can be synthesized, and these new compounds can be tested experimentally, with the goal of producing highly potent ligands acting on GPR3. The highly potent ligands (theoretically, inverse agonists) can then be used as research tools to study the functions of GPR3 and can perhaps be developed as therapeutic agents (e.g., for the treatment of Alzheimer's disease and infertility).

\section{CONCLUSIONS}

In this review, we have surveyed the current literature on GPR3, GPR6, and GPR12 and, in doing so, detailed their most significant roles in physiological functions and pathological processes. Our recent discovery highlights CBD as a novel inverse agonist for these three orphan receptors. Consequently, this offers us a new perspective from which to analyze the new molecular mechanisms of action for CBD. GPR3, GPR6, and GPR12, being novel molecular targets for CBD, may participate in CBD-induced reduction of $A \beta$ pathology, alteration of dopamine levels, inhibition of cancer cell migration, and regulation of meiotic arrest and resumption. Additional studies are warranted to further understand how GPR3, GPR6, and GPR12 mediate the CBDinduced functional changes and to uncover more potent ligands for each of these orphan receptors that can be used as research tools and perhaps novel therapeutic agents for the treatment of Alzheimer's disease, Parkinson's disease, cancer metastasis, and infertility.

\section{ACKNOWLEDGEMENTS}

This study was supported in part by the National Institutes of Health Grants DA11551 and EY13632 (to Z-HS), CA134283 (to David W Hein), and University of Louisville Research Infrastructure Fund R5385 (to Z-HS)

\section{ADDITIONAL INFORMATION}

Competing interests: The authors declare no competing interests.

Publisher's note: Springer Nature remains neutral with regard to jurisdictional claims in published maps and institutional affiliations. 


\section{REFERENCES}

1. Song ZH, Modi W, Bonner TI. Molecular cloning and chromosomal localization of human genes encoding three closely related $G$ protein-coupled receptors. Genomics. 1995;28:347-9.

2. Kostenis E. Novel clusters of receptors for sphingosine-1-phosphate, sphingosylphosphorylcholine, and (lyso)-phosphatidic acid: new receptors for "old" ligands. J Cell Biochem. 2004;92:923-36.

3. Morales P, Hurst DP, Reggio PH. Methods for the development of in silico GPCR models. In: Patricia H Reggio, editor Methods in enzymology. Vol 593. Amsterdam: Elsevier; 2017.

4. Davenport $A P$, Alexander $S$, Sharman $J L$, Pawson $A J$, Benson $H E$, Monaghan $A E_{\iota}$ et al. Class A orphans, http://www.guidetopharmacology.org/GRAC/ FamilyDisplayForward?familyld $=16$.

5. Song ZH, Laun AS. GPR3 and GPR6, novel molecular targets for cannabidiol. In: Jason B Schechter, editor 27th Annual Symposium on the cannabinoids, Montreal, QC, Canada; 2017.

6. Laun AS, Song ZH. GPR3 and GPR6, novel molecular targets for cannabidiol. Biochem Biophys Res Commun. 2017;490:17-21.

7. Brown KJ, Laun AS, Song ZH. Cannabidiol, a novel inverse agonist for GPR12. Biochem Biophys Res Commun. 2017;493:451-4.

8. Saeki $Y$, Ueno $S$, Mizuno $R$, Nishimura $T$, Fujimura $H$, Nagai $Y$, et al. Molecular cloning of a novel putative $G$ protein-coupled receptor (GPCR21) which is expressed predominantly in mouse central nervous system. FEBS Lett. 1993;336:317-22

9. Marchese A, Docherty JM, Nguyen T, Heiber M, Cheng R, Heng HH, et al. Cloning of human genes encoding novel $G$ protein-coupled receptors. Genomics. 1994;23:609-18.

10. lismaa TP, Kiefer J, Liu ML, Baker E, Sutherland GR, Shine J. Isolation and chromosomal localization of a novel human G-protein-coupled receptor (GPR3) expressed predominantly in the central nervous system. Genomics. 1994;24:391-4.

11. Eggerickx D, Denef JF, Labbe O, Hayashi Y, Refetoff S, Vassart G. et al. Molecular cloning of an orphan G-protein-coupled receptor that constitutively activates adenylate cyclase. Biochem J. 1995;309:837-43.

12. Zhang B, Ding J, Li Y, Wang J, Zhao Y, Wang W, et al. The porcine Gpr3 gene: molecular cloning, characterization and expression level in tissues and cumulus-oocyte complexes during in vitro maturation. Mol Biol Rep. 2012;39:5831-9.

13. Hinckley M, Vaccari S, Horner K, Chen R, Conti M. The G-protein-coupled receptors GPR3 and GPR12 are involved in CAMP signaling and maintenance of meiotic arrest in rodent oocytes. Dev Biol. 2005;287:249-61.

14. Thathiah A, Spittaels K, Hoffmann M, Staes M, Cohen A, Horre K, et al. The orphan $\mathrm{G}$ protein-coupled receptor 3 modulates amyloid-beta peptide generation in neurons. Science. 2009;323:946-51.

15. Song ZH, Young WS 3rd, Brownstein MJ, Bonner TI. Molecular cloning of a novel candidate $G$ protein-coupled receptor from rat brain. FEBS Lett. 1994;351:375-9.

16. Heiber M, Docherty JM, Shah G, Nguyen T, Cheng R, Heng HH, et al. Isolation of three novel human genes encoding $\mathrm{G}$ protein-coupled receptors. DNA Cell Biol. 1995;14:25-35.

17. Ignatov A, Lintzel J, Kreienkamp HJ, Schaller HC. Sphingosine-1-phosphate is a high-affinity ligand for the G protein-coupled receptor GPR6 from mouse and induces intracellular $\mathrm{Ca}^{2+}$ release by activating the sphingosine-kinase pathway. Biochem Biophys Res Commun. 2003:311:329-36.

18. Eidne KA, Zabavnik J, Peters T, Yoshida S, Anderson L, Taylor PL. Cloning, sequencing and tissue distribution of a candidate $\mathrm{G}$ protein-coupled receptor from rat pituitary gland. FEBS Lett. 1991;292:243-8.

19. Ignatov A, Lintzel J, Hermans-Borgmeyer I, Kreienkamp HJ, Joost $P$, Thomsen $S$, et al. Role of the G-protein-coupled receptor GPR12 as high-affinity receptor for sphingosylphosphorylcholine and its expression and function in brain development. J Neurosci. 2003;23:907-14.

20. Uhlenbrock K, Gassenhuber H, Kostenis E. Sphingosine 1-phosphate is a ligand of the humangpr3, gpr6 and gpr12 family of constitutively active $\mathrm{G}$ protein-coupled receptors. Cell Signal. 2002;14:941-53.

21. Bresnick JN, Skynner HA, Chapman KL, Jack AD, Zamiara E, Negulescu $P$, et al. Identification of signal transduction pathways used by orphan $\mathrm{g}$ protein-coupled receptors. Assay Drug Dev Technol. 2003;1:239-49.

22. Martin AL, Steurer MA, Aronstam RS. Constitutive activity among orphan class-A G protein coupled receptors. PLoS ONE. 2015;10:e0138463.

23. Tanaka S, Miyagi T, Dohi E, Seki T, Hide I, Sotomaru Y, et al. Developmental expression of GPR3 in rodent cerebellar granule neurons is associated with cell survival and protects neurons from various apoptotic stimuli. Neurobiol Dis. 2014;68:215-27.

24. Lu X, Zhang N, Dong $S, H u$ Y. Involvement of GPR12 in the induction of neurite outgrowth in PC12 cells. Brain Res Bull. 2012;87:30-6.
25. Lowther KM, Uliasz TF, Gotz KR, Nikolaev VO, Mehlmann LM. Regulation of constitutive GPR3 signaling and surface localization by GRK2 and beta-arrestin-2 overexpression in HEK293 cells. PLoS ONE. 2013;8:e65365.

26. Thathiah A, Horre K, Snellinx A, Vandewyer E, Huang Y, Ciesielska M, et al. Betaarrestin2 regulates Abeta generation and gamma-secretase activity in Alzheimer's disease. Nat Med. 2013;19:43-9.

27. Nelson CD, Sheng M. Gpr3 stimulates Abeta production via interactions with APP and beta-arrestin2. PLoS ONE. 2013;8:e74680.

28. Yin H, Chu A, Li W, Wang B, Shelton F, Otero F, et al. Lipid G protein-coupled receptor ligand identification using beta-arrestin PathHunter assay. J Biol Chem. 2009;284:12328-38.

29. Valverde O, Celerier E, Baranyi M, Vanderhaeghen $P$, Maldonado R, Sperlagh B, et al. GPR3 receptor, a novel actor in the emotional-like responses. PLoS ONE. 2009;4:e4704.

30. Ye C, Zhang Z, Wang Z, Hua Q, Zhang R, Xie X. Identification of a novel smallmolecule agonist for human $G$ protein-coupled receptor 3. J Pharmacol Exp Ther. 2014;349:437-43.

31. Jensen T, Elster L, Nielsen SM, Poda SB, Loechel F, Volbracht C, et al. The identification of GPR3 inverse agonist AF64394; the first small molecule inhibitor of GPR3 receptor function. Bioorg Med Chem Lett. 2014;24:5195-8.

32. Lin ZJ, Lu XM, Zhu TJ, Fang YC, Gu QQ, Zhu W. GPR12 selections of the metabolites from an endophytic Streptomyces sp. associated with Cistanches deserticola. Arch Pharm Res. 2008;31:1108-14.

33. Lin A, Lu X, Fang Y, Zhu T, Gu Q, Zhu W. Two new 5-hydroxy-2-pyrone derivatives isolated from a marine-derived fungus Aspergillus flavus. J Antibiot (Tokyo). 2008;61:245-9.

34. Du L, Zhu T, Fang Y, Gu Q, Zhu W. Unusual C25 steroid isomers with bicyclo[4.4.1] $\mathrm{A} / \mathrm{B}$ rings from a volcano ash-derived fungus Penicillium citrinum. J Nat Prod. 2008;71:1343-51.

35. Tanaka S, Ishii K, Kasai K, Yoon SO, Saeki Y. Neural expression of G proteincoupled receptors GPR3, GPR6, and GPR12 up-regulates cyclic AMP levels and promotes neurite outgrowth. J Biol Chem. 2007;282:10506-15.

36. Tanaka S, Shaikh IM, Chiocca EA, Saeki Y. The Gs-linked receptor GPR3 inhibits the proliferation of cerebellar granule cells during postnatal development. PLOS ONE. 2009:4:e5922.

37. Huang Y, Skwarek-Maruszewska A, Horre K, Vandewyer E, Wolfs L, Snellinx A, et al. Loss of GPR3 reduces the amyloid plaque burden and improves memory in Alzheimer's disease mouse models. Sci Transl Med. 2015;7:309ra164.

38. Ruiz-Medina J, Ledent C, Valverde O. GPR3 orphan receptor is involved in neuropathic pain after peripheral nerve injury and regulates morphine-induced antinociception. Neuropharmacology. 2011;61:43-50.

39. Tourino C, Valjent E, Ruiz-Medina J, Herve D, Ledent C, Valverde O. The orphan receptor GPR3 modulates the early phases of cocaine reinforcement. Br J Pharmacol. 2012;167:892-904.

40. Godlewski G, Jourdan T, Szanda G, Tam J, Resat C, Harvey-White J, et al. Mice lacking GPR3 receptors display late-onset obese phenotype due to impaired thermogenic function in brown adipose tissue. Sci Rep. 2015;5:14953.

41. Richard FJ. Regulation of meiotic maturation. J Anim Sci. 2007;85:E4-6.

42. Mehlmann LM, Saeki Y, Tanaka S, Brennan TJ, Evsikov AV, Pendola FL, et al. The Gs-linked receptor GPR3 maintains meiotic arrest in mammalian oocytes. Science. 2004:306:1947-50.

43. Norris RP, Freudzon L, Freudzon M, Hand AR, Mehlmann LM, Jaffe LA. A G(s)linked receptor maintains meiotic arrest in mouse oocytes, but luteinizing hormone does not cause meiotic resumption by terminating receptor-G(s) signaling Dev Biol. 2007;310:240-9.

44. Deng J, Lang S, Wylie C, Hammes SR. The Xenopus laevis isoform of G protein coupled receptor 3 (GPR3) is a constitutively active cell surface receptor that participates in maintaining meiotic arrest in $X$. laevis oocytes. Mol Endocrinol. 2008;22:1853-65

45. Yang CR, Wei Y, Qi ST, Chen L, Zhang QH, Ma JY, et al. The G protein coupled receptor 3 is involved in CAMP and CGMP signaling and maintenance of meiotic arrest in porcine oocytes. PLoS ONE. 2012;7:e38807.

46. Ledent C, Demeestere I, Blum D, Petermans J, Hamalainen T, Smits G, et al. Premature ovarian aging in mice deficient for Gpr3. Proc Natl Acad Sci USA 2005;102:8922-6.

47. Cai D, Qiu J, Cao Z, McAtee M, Bregman BS, Filbin MT. Neuronal cyclic AMP controls the developmental loss in ability of axons to regenerate. J Neurosci. 2001;21:4731-9.

48. Alexander JJ, Anderson AJ, Barnum SR, Stevens B, Tenner AJ. The complement cascade: Yin-Yang in neuroinflammation-neuro-protection and -degeneration. J Neurochem. 2008;107:1169-87.

49. Benoit ME, Hernandez MX, Dinh ML, Benavente F, Vasquez O, Tenner AJ. C1qinduced LRP1B and GPR6 proteins expressed early in Alzheimer disease mouse models, are essential for the C1q-mediated protection against amyloid-beta neurotoxicity. J Biol Chem. 2013;288:654-65. 
50. Oeckl P, Hengerer B, Ferger B. G-protein coupled receptor 6 deficiency alters striatal dopamine and CAMP concentrations and reduces dyskinesia in a mouse model of Parkinson's disease. Exp Neurol. 2014;257:1-9.

51. Lobo MK, Cui Y, Ostlund SB, Balleine BW, Yang XW. Genetic control of instrumental conditioning by striatopallidal neuron-specific S1P receptor Gpr6. Nat Neurosci. 2007;10:1395-7.

52. Miyagi T, Tanaka S, Hide I, Shirafuji T, Sakai N. The subcellular dynamics of the Gslinked receptor GPR3 contribute to the local activation of PKA in cerebellar granular neurons. PLoS ONE. 2016;11:e0147466.

53. Bjursell M, Gerdin AK, Jonsson M, Surve VV, Svensson L, Huang XF, et al. G protein-coupled receptor 12 deficiency results in dyslipidemia and obesity in mice. Biochem Biophys Res Commun. 2006;348:359-66.

54. Lu X, Zhang N, Meng B, Dong S, Hu Y. Involvement of GPR12 in the regulation of cell proliferation and survival. Mol Cell Biochem. 2012;366:101-10.

55. Beil M, Micoulet A, von Wichert G, Paschke S, Walther $P$, Omary $M B$, et al. Sphingosylphosphorylcholine regulates keratin network architecture and viscoelastic properties of human cancer cells. Nat Cell Biol. 2003;5:803-11.

56. Park MK, Park S, Kim HJ, Kim EJ, Kim SY, Kang GJ, et al. Novel effects of FTY720 on perinuclear reorganization of keratin network induced by sphingosylphosphorylcholine: Involvement of protein phosphatase 2A and G-protein-coupled receptor-12. Eur J Pharmacol. 2016;775:86-95.

57. Lee DK, George SR, Evans JF, Lynch KR, O'Dowd BF. Orphan G protein-coupled receptors in the CNS. Curr Opin Pharmacol. 2001;1:31-9.

58. Izzo AA, Borrelli F, Capasso R, Di Marzo V, Mechoulam R. Non-psychotropic plant cannabinoids: new therapeutic opportunities from an ancient herb. Trends Pharmacol Sci. 2009:30:515-27.

59. Zuardi AW. Cannabidiol: from an inactive cannabinoid to a drug with wide spectrum of action. Rev Bras Psiquiatr. 2008:30:271-80.
60. Pertwee R. The pharmacology and therapeutic potential of cannabidiol. In: Vincenzo Di Marzo, editor. Cannabinoids; New York, NY USA, Springer; 2004. p. 32-83.

61. Pertwee RG. The diverse $C B 1$ and $C B 2$ receptor pharmacology of three plant cannabinoids: delta9-tetrahydrocannabinol, cannabidiol and delta9tetrahydrocannabivarin. Br J Pharmacol. 2008;153:199-215.

62. Laprairie RB, Bagher AM, Kelly ME, Denovan-Wright EM. Cannabidiol is a negative allosteric modulator of the cannabinoid $\mathrm{CB} 1$ receptor. $\mathrm{Br} J$ Pharmacol. 2015;172:4790-805.

63. Russo EB, Burnett A, Hall B, Parker KK. Agonistic properties of cannabidiol at 5HT1a receptors. Neurochem Res. 2005;30:1037-43.

64. Campos AC, Guimaraes FS. Involvement of 5HT1A receptors in the anxiolytic-like effects of cannabidiol injected into the dorsolateral periaqueductal gray of rats. Psychopharmacology. 2008;199:223-30.

65. Yang KH, Galadari S, Isaev D, Petroianu G, Shippenberg TS, Oz M. The nonpsychoactive cannabinoid cannabidiol inhibits 5-hydroxytryptamine3A receptormediated currents in Xenopus laevis oocytes. J Pharmacol Exp Ther. 2010;333:547-54.

66. Ryberg E, Larsson N, Sjogren S, Hjorth S, Hermansson NO, Leonova J, et al. The orphan receptor GPR55 is a novel cannabinoid receptor. $\mathrm{Br} J$ Pharmacol. 2007;152:1092-101.

67. Kathmann M, Flau K, Redmer A, Trankle C, Schlicker E. Cannabidiol is an allosteric modulator at mu- and delta-opioid receptors. Naunyn Schmiede Arch Pharmacol. 2006;372:354-61.

68. Rong C, Lee Y, Carmona NE, Cha DS, Ragguett RM, Rosenblat JD, et al. Cannabidiol in medical marijuana: research vistas and potential opportunities. Pharmacol Res. 2017;121:213-8. 